\title{
Relapsing polychondritis
}

INSERM

\section{Source}

INSERM. (1999). Orphanet: an online rare disease and orphan drug data base. Relapsing polychondritis. ORPHA:728

Relapsing polychondritis (RP) is a rare, clinically heterogeneous, multisystemic inflammatory disease characterized by inflammation of the cartilage and proteoglycan rich structures leading to cartilage damage with joint, ocular and cardiovascular involvement. 